\title{
Ultrastructural observation on sterilization of melittin
}

\author{
WANG GuanLin*, NA Jie, PAN LingZi, XING Zhuo \& FANG HongJun \\ College of Life Science, Liaoning Normal University, Dalian 116029, China \\ Received March 20, 2010; accepted July 28, 2010
}

\begin{abstract}
The effects of melittin on growth and bacteriostasis of four pathogens were extensively investigated using scanning electron microscopy (SEM) and transmission electron microscopy (TEM). The results indicated that the melittin had a marked bacteriostatic effect on the four pathogenic bacteria. Among these, E. cacotowora was influenced most powerfully and quickly, the yeast and $F$. fulva were the second, and the $S$. aureus was inhibited by a low concentration but was killed by a high concentration. It was observed in the experiments that melittin killed pathogenic bacteria in three ways. One was by pore formation. After integrating melittin into the plasma membrane, a vacuole was formed then penetrated, resulting in bacterial content leakage. The vacuole also experienced plasmolysis and the growing cavity destroyed the membrane. A third effect was the formation of vacuoles in the cells which induced the pycnosis of the cytoplasm resulting in a cell death. The mechanism of melittin bacteriostasis was the result of integrating melittin with phospholipod double layers of the plasmalemma and the endomembranes.
\end{abstract}

\section{Melittin, pathogens, ultrastructural alterations, bacteriostasis mechanism}

Citation: Wang G L, Na J, Pan L Z, et al. Ultrastructural observation on sterilization of melittin. Sci China Life Sci, 2011, 54: 166-170, doi: 10.1007/s11427010-4118-x

The antimicrobial peptides, cecropins, were originally isolated from silkworms by the Swedish scientist Human G. in 1980 [1]. Pharacologists regarded them as possible low resistence as antibiotics [2]. Various studies have been concerned with the antimicrobial mechanism. Benachir considered that the affinity of melittin for phosphatidylcholine vesicles was responsible for the increasing melittin-induced leakage from cholesterolcontaining membranes, and an allor-none hypothesis was proposed [3]. The Shai-MatsuzakiHuang (SMH) model proposed that the interaction of the peptide with the membrane was followed by the displacement of lipids [4-8]. Five hypotheses concerning the possible mechanisms for antimicrobial peptide action [3] were summarized in Nature. However, the mechanisms of antimicrobial peptide action mentioned above are based on the study on cecropins, with related few reports concerning other varieties of antimicrobial peptides.

Melittin is an insect antimicrobial peptide with an especially sterilization capacity. Melittin has broad-spectrum,

*Corresponding author (email: guanlinwang@ 163.com) fast-acting and highly effective inhibitory effects on both pathogenic and agricultural microorganisms, which demonstrated its application potential as a biological pesticide [9]. There has been no systematic research regarding the mechanism of melittin action at the ultrastructural level, nor has any direct physical evidence been confirmed. We studied the ultrastructural changes of bacteria, yeast and fungi after their interaction with melittin, and tried to find more visual evidence in order to both confirm the hypothesis concerning physiological and biochemical aspects, and also explore the mechanism of the interactions between melittin and various pathogens.

\section{Materials and methods}

\subsection{Materials}

\subsubsection{Strains}

Erwinia carotovora and Fulvia fulva were obtained from the Chinese Agricultural Academy of Sciences and Shen- 
yang Agriculture University. Staphylococcus aureus and Escherichia coli were obtained from CMCC and GS115 from TaKaRa.

\subsubsection{Melittin sample preparation}

Melittin prepared as $0.25 \mathrm{mg} \mathrm{mL}^{-1}$ stock solution in $0.9 \%$ $\mathrm{NaCl}$ was purchased from Baiyunshan Pharmaceutical Company in China.

\subsection{Methods}

\subsubsection{Microbial culturing and growth curves}

Sample groups in LB media were either composed of $2 \mathrm{~mL}$ melittin $\left(0.25 \mathrm{mg} \mathrm{mL}^{-1}\right)$ or $2 \mathrm{~mL}$ sterilized water (blank control). Erwinia carotowora, Staphylococcus aureus, GS115 and Fulvia fulva in the logarithmic growth stage were each added into both groups $(0.4 \mathrm{~mL})$ which were cultured synchronously. $A_{600}$ was determined spectrophotometrically after respectively being cultured for $0,1,2,4,8$ and $12 \mathrm{~h}$. The percentage of antibacterial potency was calculated according to the equation ( $A_{600}$ of 0 hour $-A_{600}$ of $x$ hour $) / A_{600}$ of $x$ hour $\times 100 \%$ (here, $x$ indicates definite incubation hours). Data obtained in this study were all obtained after being repeated 3 times. Differences between groups were analyzed using SPSS 10.0, which was expressed as the average \pm standard error $(\bar{x} \pm \mathrm{SE})$.

\subsubsection{Sample preparation}

Pathogen at logarithm growth was added to LB media with melittin $\left(0.125 \mathrm{mg} \mathrm{mL}^{-1}\right.$ and $\left.0.25 \mathrm{mg} \mathrm{mL}^{-1}\right)$, and swayedly cultured. After being cultured for respectively 1, 4, 8 and $12 \mathrm{~h}$, samples were harvested for observation. The control group was prepared and observed following the same procedure described above.

\subsubsection{Electron microscopy observation}

The concentrated pathogens were fixed with glutaraldehyde for at least $2 \mathrm{~h}$. The samples were prepared according to the methods of sample preparation for transmission electron microscope scanning [10].

\section{Results and analysis}

\subsection{Inhibitory effects of melittin on different pathogens}

After incubation for $24 \mathrm{~h}$, the addition of melittin rapidly affected the growth of four kinds of pathogens, while the control group grew at a normal rate. In order to compare the sensitivities of different strains to melittin, the changes of $A_{600}$ Value were tested, and the percentages of antibacterial efficiency were calculated. The effect of melittin on pathogens is shown in Figure 1. Compared with the control group, the $A_{600}$ value of Erwinia carotovora with melittin decreased from 0.24 to 0.01 within $1 \mathrm{~h}$ and remained at the value of 0.01 for more than $12 \mathrm{~h}$, which changed the sterilization percentage to $95.8 \%$. However, the $A_{600}$ value of Staphylococcus aureus with melittin decreased to 0.10 within $1 \mathrm{~h}$ and decreased to $0.044 \mathrm{~h}$ later, which changed the sterilization percentage to $85.1 \%$. But $8 \mathrm{~h}$ later, the $A_{600}$ value was increased to 0.07 , decreasing the percentage to $60.3 \%$, which meant that melittin exhibited inhibitory action solely at low concentrations. When the concentration of melittin doubled, there was no growth recovered with $95 \%$ inhibition. The inhibitory percentage of GS115 with melittin was observed after $1 \mathrm{~h}$ at $25.2 \%, 4 \mathrm{~h}$ at $50.0 \%$ and $8 \mathrm{~h}$ with $92.2 \%$. For Fulvia fulva, the inhibitory action was $19.4 \%$ after $1 \mathrm{~h}, 46.6 \%$ after $4 \mathrm{~h}$ and $94.1 \%$ after $12 \mathrm{~h}$. The growth of both GS115 and Fulvia fulva was not recovered after $24 \mathrm{~h}$.

It was suggested that melittin might have directly killed Erwinia carotovora, GS115 and Fulvia fulva rather than inhibiting the growth, with the rapid inhibitory action of melittin on Staphylococcus aureus exclusively at its lowest concentration.

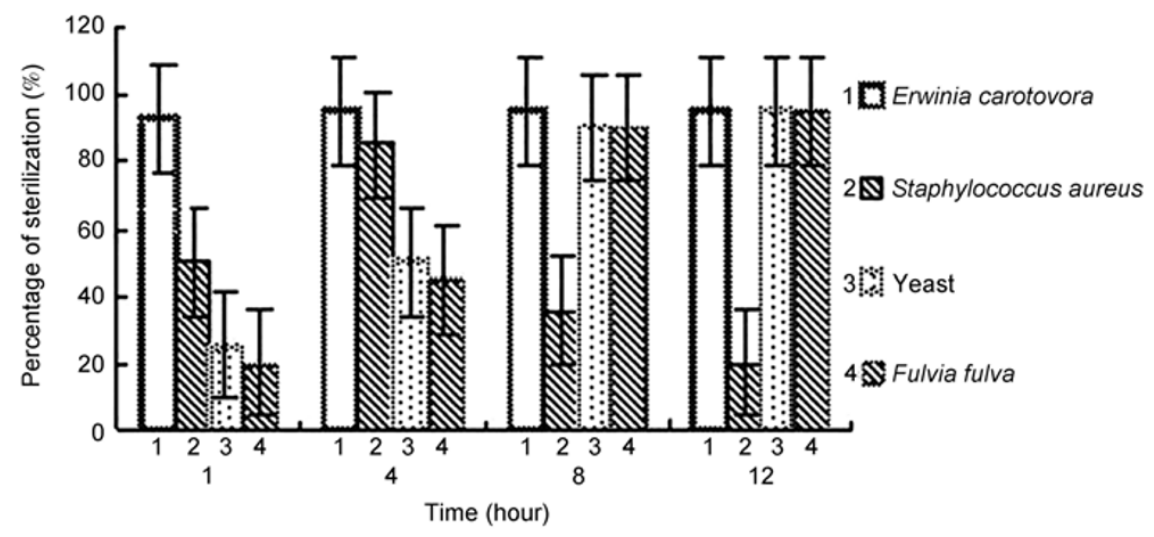

Figure 1 Comparison of inhibitory percentage of melittin on pathogens. 


\subsection{Electron microscope observation of bacteria}

\subsubsection{Ultrastructure changes of Erwinia carotowora in} response to the bacteriostatic action of melittin

The healthy cell membrane of Erwinia carotowora is typically intact and slick, the cell structure is compact and inerratic, and the cytoplasm is well-proportioned. By contrast, the configuration of melittin affect Erwinia carotowora was transfigured after $4 \mathrm{~h}$, the cytoplasm was no longer well-proportioned, contracting and gathering, vacuoles appeared in the inner of the cell (Figure 2A), as well as holes in the cell membranes (Figure 2B). Each hole pierced through the cell membrane from the inside to the outside (Figure 2C). With the increase of intensity, the holes gradually expanded. The proliferation of holes resulted in the fragmentary of membranes, and leaking of cell contents. Ultimately, the pathogens cracked and died (Figure 2A).
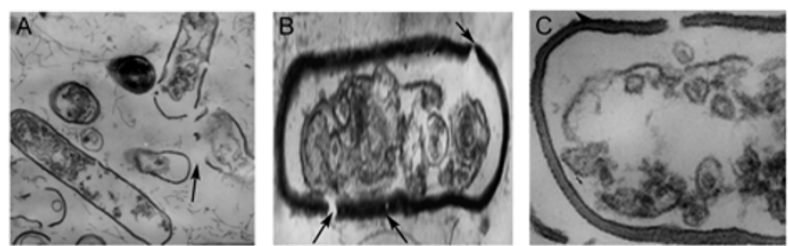

Figure 2 Interior structure of Erwinia carotowora under a transmission electron microscope. A, Erwinia carotowora affected by melittin for $1 \mathrm{~h}$ ( $\times 8000)$; B, Erwinia carotowora affected by melittin for $1 \mathrm{~h}(\times 300000)$; C, Erwinia carotowora affected by melittin for $4 \mathrm{~h}(\times 500000)$.

\subsubsection{Ultrastructure changes of Staphylococcus aureus in} response to the bacteriostatic action of melittin

Healthy Staphylococcus aureus is a well-stacked ball with a smooth surface and compact, well-propotioned cytoplasm (Figure 3A). Following $4 \mathrm{~h}$ under the influence of melittin, small vacuoles were seen on the cell membrane of Staphylococcus aureus, with the vacuoles looking like bubbles gradually extended towards both sides of membrane, with adjacent vacuoles connected to form larger vacuoles between the cell wall and the cytoplasm, a further expanded (Figure 3B). The cytoplasm sharply contracted, accompanied by plasmolysis, which caused cell death (Figure 3C).

\subsubsection{Scanning electron microscope observation of} Staphylococcus aureus and Erwinia carotowora

The typical cell membrane of Staphylococcus aureus and
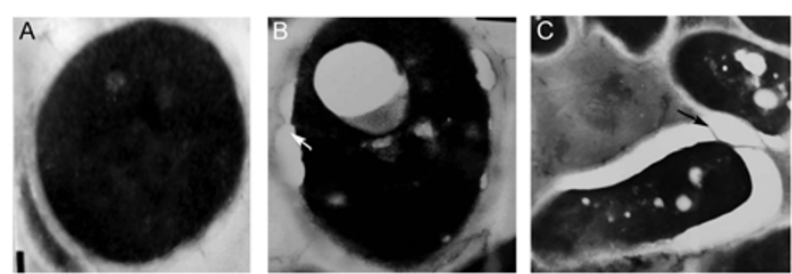

Figure 3 Interior structure of Staphylococcus aureus under a transmission electron microscope. A, healthy Staphylococcus aureus $(\times 20000)$; B, Staphylococcus aureus affected by melittin for $1 \mathrm{~h}(\times 20000)$; C, Staphylococcus aureus affected by melittin for $4 \mathrm{~h}(\times 10000)$.
Erwinia carotowora is bacilliform, slick and full when observed by a scanning electron microscope (Figures $4 \mathrm{~A}$ and $5 \mathrm{~A})$. Following being affected by melittin for $4 \mathrm{~h}$, the configuration was deformed, the surface became rough, toothed and then began to decompose. The remanet mass was observed and all pathogens died (Figure 4B). The cell contents leaked out, which buried the cell in kytoplasm (Figure 5B).
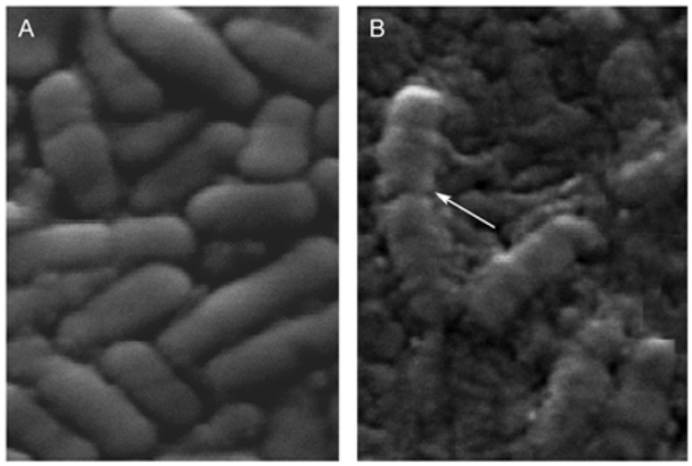

Figure 4 Exterior configuration of Erwinia carotowora under a scanning electron microscope. A, normal Erwinia carotowora $(\times 10000)$; B, Erwinia carotowora affected by melittin for $1 \mathrm{~h}(\times 10000)$.
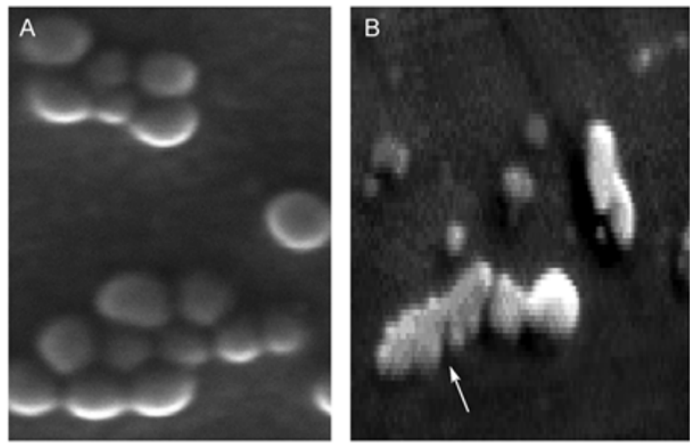

Figure 5 Exterior configuration of Staphylococcus aureus under a scanning electron microscope. A, healthy Staphylococcus aureus $(\times 10000)$; B, Staphylococcus aureus affected by melittin for $1 \mathrm{~h}(\times 10000)$.

\subsection{Electron microscope observation of yeast GS115}

Healthy yeast looks like an energetic ball with a smooth surface, compact and well-propotioned cytoplasm (Figure $6 \mathrm{~B})$. Many vacuoles appeared at the cell membrane (Figure 6A), which gradually expanded both inside and outside, and then the membrane broke though. Inward expansion made cytoplasm scatter to form a cavity. Cytoplasm and various enzymes were leaked into the area between the the membrane and the cell wall, which disintegrated the cell wall (Figure 6C). The proliferating holes made the cell membrane and the cell wall no longer viable with the cell content lost, cell cracked and dead (Figure 6D).

Healthy yeast is spherical with a smooth surface (Figure 7A). After $4 \mathrm{~h}$ of being affected with melittin, the cell sur- 

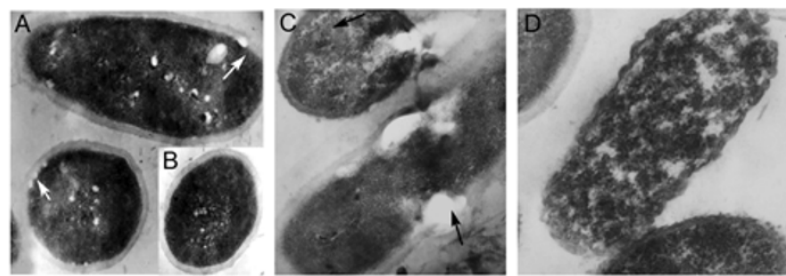

Figure 6 Interior structure of yeast under a transmission electron microscope. A, yeast affected by melittin for $1 \mathrm{~h}(\times 10000)$; B, healthy yeast $(\times 6000)$; C, yeast affected by melittin for $4 \mathrm{~h}(\times 10000)$; D, yeast affected by melittin for $8 \mathrm{~h}(\times 10000)$
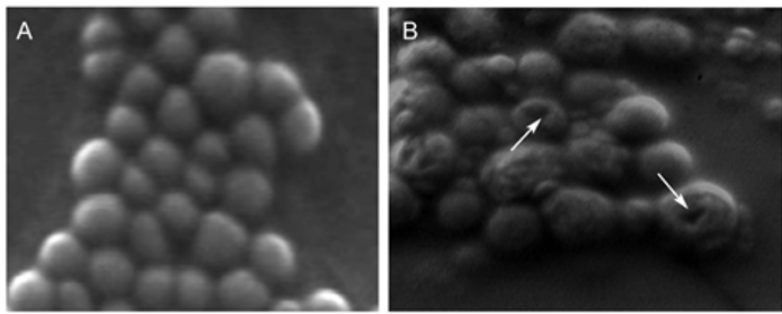

Figure 7 Exterior configuration of Erwinia carotowora under a scanning electron microscope. A, healthy yeast $(\times 10000)$; $\mathrm{B}$, yeast affected by melittin for $4 \mathrm{~h}(\times 10000)$

face become quite rough, and disintegrated. Holes which extended from the inner to the outer membrane were observed with SEM, the contents leaked, and the cell died (Figure 7B).

\subsection{Electron microscope observation of fungi}

The cross section of healthy spores of Fulvia fulva is nearly round, inerratic; the cell wall is thick, the raphe-like tuber in its tegument is well-proportioned; the cytoplasm is regular (Figure 8A). By contrast, fuugi of the group affected by melittin became crimped and distorted, the cytoplasm contracted, the cavum emerged, the cytoplasm and cell wall separated, and the tuber disappeared (Figure 8B).
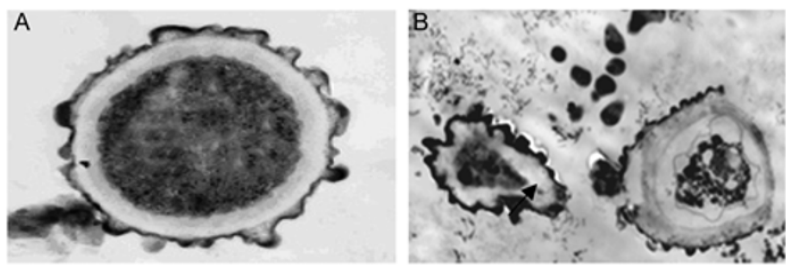

Figure 8 Interior structure of Fulvia fulva under a transmission electronmicroscope. A, healthy Fulvia fulva $(\times 40000)$; B, Fulvia fulva affected by melittin for $12 \mathrm{~h}(\times 30000)$.

Contrasting with the control, the pathogens configuration was markedly affected by melitiin after $24 \mathrm{~h}$. The involved fungus was distorted, the cell surface was irregular, the granule in it disappeared, and the exterior crimped and partially split (Figures 9A and B).
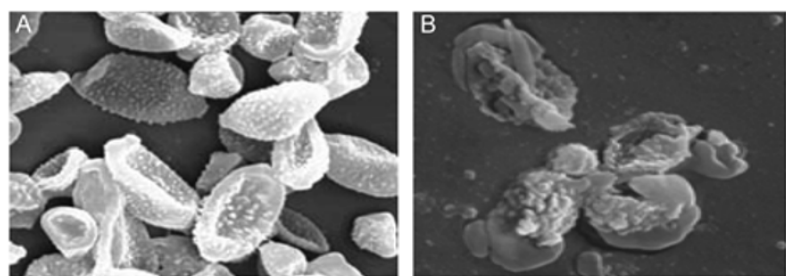

Figure 9 Exterior configuration of Fulvia fulva under a scanning electronmicroscope. A, healthy Fulvia fulva (×9000); B, Fulvia fulva affected by melittin for $12 \mathrm{~h}(\times 9000)$.

\section{Discussion}

\subsection{Analysis of membrane punching hypothesis}

According to the results obtained from biochemistry and molecular biology, 5 kinds of hypothesis were proposed for the possible sterilization mechanism of antimicrobial peptide [4]. We observed the entire process under SEM and TEM for the first time, in the course of which the pathogens deformed, the membrane punched, the cell walls disintegrated, with the pores increased in size and number, the cytoplasm leaked, and the cells died. The results confirmed the view of melittin punching in the membrane. The interaction of melittin with yeast and bacteria were very clear. In our experiments we also observed the formation of holes with clear edges in the membrane. Melittin permeates the cell wall to affect the membrane. Initially, a vacuole with a diameter of approximately $30 \mathrm{~nm}$ formed in the center of the cell membrane. After the diameter of plasm side constantly expanded up to $70 \mathrm{~nm}$, the vacuole penetrated the cell wall from inside to outside, forming a clear structure analogous to an electric drill hole. We selected four common pathogens, including Staphylococcus aureus, Erwinia carotowora, yeast and Fulvia fulva, to research their interaction with melittin under an electron microscope. From the changes of ultrastructure we observed, it was concluded that melittin penetrated the cell wall and affected the cell membrane and the cytoplasm, in which enzymes and acceptors were included. There are several possible models for the interaction of melittin with the membrane: drilling holes, breaking out, or rolling up, which were observed in different strains. The influence of melittin on the cytoplasm led it to contract, and then triggered apoptosis. There were differences in the mechanism between species in the process of melittin's action on the membrane and the cytoplasm, which might be derived from minute differences in membrane structure. The cell walls of such fungi as Fulvia fulva may be broken down after interaction with melittin. It was also discovered that the membrane punching mechanism also involved the barrel-stave model and the toroidal model [11], which may require further elucidation.

\subsection{Interrelation between the action and speed or de- gree in bacteriosis of melittin}

The study above indicated that melittin had different kinds 
of actions on various pathogens. It was observed that there were differences in the strength of the interaction with melittin among the different pathogens. The $A_{600}$ value of $\mathrm{Er}$ winia carotovora with melittin was decreased from 0.24 to 0.01 within $1 \mathrm{~h}$ and remained at 0.01 until $12 \mathrm{~h}$ later, which changed the percentage of sterilization to $95.8 \%$. However, the $A_{600}$ value of Staphylococcus aureaus with melittin decreased to 0.10 within $1 \mathrm{~h}$ and to $0.044 \mathrm{~h}$ later, which changed the percentage of sterilization to $85.1 \%$. But $8 \mathrm{~h}$ later, the $A_{600}$ value was increased to 0.07 , which changed the percentage to $60.3 \%$, signifying that inhibited solely at low concentration. When double concentration were taken, there was no growth recovered with an inhibory percentage of $95 \%$. The inhibitory percentage of melittin on GS115 was $25.2 \%$ after being treating for $1 \mathrm{~h}, 50.0 \%$ after $4 \mathrm{~h}$ and $92.2 \%$. after 8 h. The same influence on Fulvia fulva $19.4 \%$ after $1 \mathrm{~h}, 46.6 \%$ after $4 \mathrm{~h}$ and $94.1 \%$ after $12 \mathrm{~h}$. Both GS 115 and Fulvia fulva had no recovery growth after being incubating for $24 \mathrm{~h}$. There was apparently a direct relationshio between the active strength and the time course. The "Punching model" may lead to various bacteriostasis quickly and effectively [11]. The "Plasmolysis model" was weak, while the "Cytoplasmic-cavity model" was strong but slow. Whether or not the observed phenomenon was universal requies experimental conformation.

From the above comprehensive study, we propose that all of the interactions between melittin and pathogens directly influence on the cell membrane [3].

1 Boman H G, Agerbeth B, Boman A. Mechanisms of action on Escherichia coli of cecropinPI and PR-39, two antibacterial peptides from pig intestine. Infect Immun, 1993, 61: 2978-2984

2 Fennell J F, Shipman W H, Cole L J. Antibacterial action of a bee venom fraction (melittin) against a penicillin-resistant staphylococcus and other microorganisms. Res Dev Tech Rep, 1967, 1967: 1-13

3 Zasloff M. Antimicrobial peptides of multicellular organisms. Nature, 2002, 415: 389-395

4 Matsuzaki K. Why and how are peptide-lipid interactions utilized for self-defense? Magainins and tachyplesins as archetypes. Biochim Biophys Acta, 1999, 1462: 1-10

5 Yang L, Weiss T M, Lehrer R I, et al. Crystallization of antimicrobial pores in membranes: magainin and protegrin. Biophys J, 2000, 79: 2002-2009

6 Westerhoff $\mathrm{H} \mathrm{V}$, Juretic D, Hendler R W, et al. Magainins and the disruption of membrane-linked free-energy transduction. Proc Natl Acad Sci USA, 1989, 86: 6597-6601

7 Bierbaum G, Sahl H G. Induction of autolysis of Staphylocci by the basic peptide antibiotics pep5 and nisin and their influence on the activity of autolytic enzymes. Arch Microbiol, 1985, 141: 249-254

8 Kragol G. The antibacterial peptide pyrrhocoricin inhibits the ATPase actions of DnaK and prevents chaperone-assisted protein folding. Biochem, 2001, 40: 3016-3026

9 Pan L Z, Na J, Xing Z, et al. Inhibiting effect of melittin on pathogens of crops.Chinese Sci Bull, 2007, 52: 639-644

10 Tang X M, Tai S S. ESEM observation for biological samples. J Chinese electr micros soc, 2001, 20: 217-223

11 Yang L, Weiss T M, Lehrer R I. Crystallization of antimicrobial pores in membranes:magainin and protegrin. Biophys J, 2000, 79: 2002-2009

Open Access This article is distributed under the terms of the Creative Commons Attribution License which permits any use, distribution, and reproduction in any medium, provided the original author(s) and source are credited. 